8 Appelman CLM, Bossen PC, Dunk JHM, Lisdonk EH, de Melker RA, van Weert HCPM. NHG standard otitis media acuta. (Guideline on acute otitis media of the Dutch College of General Practitioners.) Huisarts Wet 1990;33:242-5.

9 Hoberman A, Paradise JL, Burch DJ, Valinski WA, Hedrick JA, Aronovitz $\mathrm{GH}$, et al. Equivalent efficacy and reduced occurrence of diarrhea from a new formulation of amoxicillin/clavulanate potassium for treatment of acute otitis media in children. Pediatr Infect Dis J 1997;16:463-70.

10 Laxdal OE, Merida J, Jones RHT. Treatment of acute otitis media: a controlled study of 142 children. Can Med Assoc J 1970;102:263-8.

11 Mandel EM, Casselbrant ML, Rockette HE, Bluestone CD, Kurs-Lasky M. Efficacy of 20- versus 10-day antimicrobial treatment for acute otitis media. Pediatrics 1995;96:5-13.

12 Alho OP, Laara E, Oja $\mathrm{H}$. What is the natural course of recurrent acute otitis media in infancy? J Fam Pract 1996;43:258-64.

13 Iino Y, Nakamura Y, Koizumi T, Toriyama M. Prognostic factors for persistent middle ear effusion after acute otitis media in children. Acta Otolaryngol (Stockh) 1993;113:761-5.

14 Hathaway TJ, Katz HP, Dershewitz R, Marx TJ. Acute otitis media: who needs posttreatment follow-up? Pediatrics 1994;94:143-7.

15 Damoiseaux RAMJ, van Balen FAM, Hoes AW, de Melker RA. Antibiotic treatment of acute otitis media in children under two years of age: treatment of acute otitis media in children
evidence based? Br J Gen Pract 1998;48:1861-4.

16 Wormald PJ, Browning GG, Robinson K. Is otoscopy reliable? A structured teaching method to improve otoscopic accuracy in trainees. Clin Otolaryngol 1995;20:63-7.
17 Jerger J. Clinical experience with impedance audiometry. Arch Otolaryngol 1970;92:311-24.

18 Zielhuis GA, Heuvelmans-Heinen EW, Rach GH, van den Broek P. Environmental risk factors for otitis media with effusion in preschool children. Scand J Prim Health Care 1989;7:33-8.

19 Kaleida PH, Casselbrant ML, Rockette HE, Paradise JL, Bluestone CD, Blatter MM, et al. Amoxicillin or myringotomy or both for acute otitis media: results of a randomized clinical trial. Pediatrics 1991;87:466-74.

20 Kontiokari T, Koivunen P, Niemela M, Pokka T, Uhari M. Symptoms of acute otitis media. Pediatr Infect Dis J 1998;17:676-9.

21 Bruijnzeels MA, van Suijlekom-Smit LWA, van der Velden J, van der Wouden JC. The child in general practice. Dutch national study of morbidity and interventions in general practice. Utrecht: NIVEL, 1993.

22 Berman S. Otitis media in children. N Engl J Med 1995;332:1560-5.

23 Hermans PWM, Sluijter M, Elzenaar K, van Veen A, Schonkeren JJM, Nooren FM, et al. Penicillin-resistant Streptococcus pneumoniae in the Netherlands: results of a 1-year molecular epidemiologic survey. J Infect Dis 1997;175:1413-22.

24 Rothrock SG, Harper MB, Green SM, Clark MC, Bachur R, Mcllmail DP, et al. Do oral antibiotics prevent meningitis and serious bacterial infections in children with streptococcus pneumoniae occult bacteremia? A meta-analysis. Pediatrics 1997;99:438-44.

(Accepted 11 November 1999)

\title{
General practice--time for a new definition
}

\author{
Frede Olesen, Jim Dickinson, Per Hjortdahl
}

Editorial by Heath and others

Research Unit for General Practice, University of

Aarhus, Vennelyst Boulevard 6,

DK-8000 Aarhus C, Denmark

Frede Olesen

professor

Department of Community and Family Medicine,

Chinese University

of Hong Kong,

Hong Kong

Jim Dickinson

professor

Department of

Community and

Family Medicine,

University of Oslo,

Norway

Per Hjortdahl

professor

Correspondence to:

F Olesen

fo@alm.au.dk

BMJ 2000;320:354-7
After some 30 years of medical development focusing largely on hospitals, organ specialisation, and high technology, the 1960s saw the revitalisation of general practice (in some countries known as family practicesee note at the end of the article), allowing this field of medicine to develop into a cornerstone of the healthcare system. At the end of the millennium academic general practice is now established in all developed countries. General practice is recognised as a special discipline and in many countries as a medical specialty equally important as and complementary to other specialties. Participation in specific training programmes has therefore become mandatory for anyone who wishes to become a specialist in this field.

The time has come to reflect on the education of general practitioners, which depends on the scientific content of general practice. A proper starting point is to consider the ideal content of the discipline as it would be described in a definition.

\section{Old definitions of general practice}

Many definitions of primary care and general practice have been proposed..$^{1-5}$ One of the most frequently quoted is the Leeuwenhorst definition from 1974: "The general practitioner is a licensed medical graduate who gives personal, primary and continuing care to individuals, families and a practice population irrespective of age, sex and illness. It is the synthesis of these functions which is unique." Other definitions also focus on the patient as an individual in a family and cultural context, continuity of care, and the sustained relationship with patients. Hence most textbooks describe the particulars of the general practitioner in terms of working methods such as continuity, comprehensiveness, work in a society (or even in patients' homes), a family approach, and good communication. ${ }^{6}$ Early definitions and descriptions of

\section{Summary points}

It is time to create a new definition of general practice based on the ideal content of the specialty

Any new definition should describe the core content and function of general practice and should supplement the description of the medical discipline

It should also be universal, not country specific

It should provide a framework for teaching and training and describe where to find evidence to support science based work

A new proposed definition fulfils these criteria, emphasising the need for general practitioners to be able to take a biomedical, psychological, and social approach to patients and their problems

general practice gave prominence to systems, settings, and methods creating opportunities for good general practice.

We question whether these dimensions in themselves distinguish between those doctors who are general practitioners and those who are not. Not only that, but they may hamper change and promote failure. They are rooted in a model of long term, full time, year round service in a stable community. Although rewarding for the doctor, this is a difficult role, with high personal and social costs for doctors in a modern society.

We contend that many definitions confuse the setting with the role and the person. They do not help us in defining the academic agenda for universities or 


\section{A definition of general practice should:}

- Describe the core content and function of the discipline to identify the specific characteristics of the clinical work

- Be supplementary to the description of the medical discipline and accept that overlaps exist between many medical specialties

- Be universal, independent of country specific

systems, settings, or working methods

- Provide a framework for the content of teaching and training

- Describe where evidence must be sought to develop the best science based core function

professional bodies when training young doctors to become general practitioners.

\section{Why should we define the discipline?}

Definitions may set the boundaries to delineate one field from others, but this is difficult for medical specialties, which inevitably have unclear overlapping boundaries. It is more important to define the centre of the discipline positively, necessarily accepting the overlap with what is required of good doctors in other fields. The definition then provides a framework for research, teaching, and development (box).

We may therefore ask what makes the difference between a surgeon or a young trainee doctor working in the front line and a specialist in general practice. In some countries healthcare systems prevent an individual general practitioner from giving continuity of care. Does this imply that these doctors cannot be good specialists in general practice? Is a doctor who is working in a healthcare system in which he or she is unable to give comprehensive primary care for paediatric or gynaecological problems not a proper general practitioner?

In parts of the world general practitioners may work in specific situations-for example, in emergency departments or in pain clinics-adding new dimensions to care even though there is minimal continuity, longitudinal care, family approach, or comprehensive care. In these cases the doctor is still performing specific functions as a specially trained general practitioner. ${ }^{7-10}$ Even in these restricted settings, the general practitioner reaches an understanding of the patient and his or her illness on the basis not only of symptoms and signs but of social and psychological factors relating to the patient and his or her background.

Each consultation may be like a frame from a film, with each sickness episode like a scene in the film, but good general practitioners are aware that these are merely excerpts from the overall drama, and they consider them as part of the total background in their decision making. Each person is treated not as a biomedical entity alone, but rather as a unique member of society.

General practitioners are aware of their role as key providers and organisers of services within the entire healthcare system, ensuring that needs are met, even if it is not always they who meet these needs. ${ }^{9}{ }^{10}$

\section{A new definition}

We believe that the time is now ripe for a more widely applicable and generalisable definition (box). Our suggested definition emphasises the core content of the discipline and the fields where the general practitioner should function as a scientifically well founded and personally capable clinician or specialist. The definition therefore has implications for research and teaching and potentially for the entire organisation of the healthcare system.

Adequate training must be provided for general practitioners to help them to become responsible members of the healthcare system. Furthermore general practitioners must honour the concept of equity-that is, giving patients equal access to equal services for equal needs-while paying attention to the need for setting medical priorities and showing due responsibility for appropriate use of resources. ${ }^{11}$ This is best achieved in systems that offer controlled access to specialists, preferably secured via a "gatekeeping" system staffed by general practitioners who know their duties and limitations. ${ }^{12}$ Where gatekeeping roles do not exist, a very important function is still to help patients to choose and obtain appropriate care from different parts of the system. Moreover, the definition implies that a general practitioner's attention and effort must embrace the entire field of care-from prevention through detection of the first symptom to eventual palliation. This must be reflected in a balanced research agenda and training curriculum.

The sciences underlying the proposed biopsychosocial approach are crucial. General practitioners should at any time be able to take an explicit, simultaneous, and interactive scientific approach to a problem from any of these three perspectives (biomedical, psychological, and social), and they should be able to combine these approaches to reach a full understanding.

Much good primary care research has focused on the biomedical aspect of illnesses as they present in primary care, and the ability to handle the biomedical component is evidently necessary for any general practitioner. However, general practitioners know that elements of the patient's personality and his or her relations to society have a major role in disease and illness. $^{7-10}$ These elements should be taught, but teaching the psychological and social aspects of medical care still rests more on common sense than on hard evidence.

\section{Suggested new definition of general practice}

"The general practitioner is a specialist trained to work in the front line of a healthcare system and to take the initial steps to provide care for any health problem(s) that patients may have. The general practitioner takes care of individuals in a society, irrespective of the patient's type of disease or other personal and social characteristics, and organises the resources available in the healthcare system to the best advantage of the patients. The general practitioner engages with autonomous individuals across the fields of prevention, diagnosis, cure, care, and palliation, using and integrating the sciences of biomedicine, medical psychology, and medical sociology." 
We must therefore ask ourselves what the necessary scientific core curriculum is for general practitioners within the fields of medical psychology and medical sociology. How can this lead to applied knowledge and skills in the general practice setting? In what areas can we simply adapt the theories and evidence of these academic disciplines, and in what areas do we also need to consider new scientific evidence based on our own research?

General practitioners are sometimes sceptical about the concept of evidence based medicine. One reason is that many have not realised that general practitioners themselves can create methodologically sound evidence within most of the different parts of the core contents of the discipline. Evidence is not limited to the biomedical aspects and certainly not to randomised controlled studies. ${ }^{13}$ An evidence based scientific approach is feasible in most cases when addressing concepts like continuity of care, communication skills, coping, empowerment, enabling, health beliefs, health promotion ("salutogenesis"), somatisation of feelings, and personality traits. ${ }^{14-18}$ The general practitioner must acquire knowledge from the fields of medical sociology and anthropology to enable him or her to diagnose how patients' conditions are shaped by their culture, family, and others in their networks and relations with society at large, including their working environments. This knowledge should be explicit, scientifically based, and theoretically sound and should be understood to a degree where it can be turned into appropriate clinical skills in diagnosis, cure, care, and palliation. ${ }^{13-16}$ This is not easy and requires work-hard but necessary if science is to be the basis of clinical work in general practice.

\section{Tools and methods}

The broad approach advocated above implies that today's focus on diagnosis must give way partially to a more patient centred approach, which should be reflected in research, teaching, training, and daily clinical work. Patients are unique and autonomous and experience life from their own perspective. ${ }^{9}{ }^{10}$ In refer-

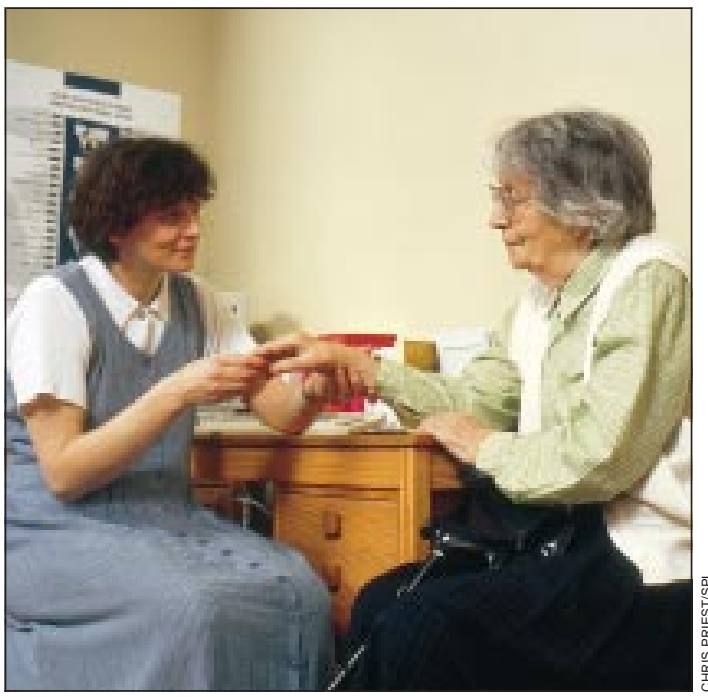

Time to reflect on general practice: practitioners need to take a biomedical, psychological, and social approach to patients and their problems
Teaching and training for general practice should:

- Be based on academic research and evidence about all core functions described in the definition

- Train the doctor to be part of an integrated and comprehensive healthcare system

- Be based on adapted evidence from the biomedical, psychological, and social sciences

- Have a balanced agenda across prevention, diagnosis, cure, care, and palliation

ring to this, our proposed definition implies that we need greater academic insight into such areas as medical ethics. Such insight will emerge only if we deploy theories and knowledge from the humanities while at the same time pursuing new strands of research and learning tailored to clinical life in general practice. This process is not yet reflected in the training of general practitioners.

General practitioners have responsibility for optimising the total use of healthcare resources to ensure the best possible access for those in need of care. Policy settings promote or limit the roles and activities of general practitioners, often in unexpected ways. Policy can be improved only if the role of general practitioners in the population is fully appreciated, and members of the specialty must therefore undertake health services research, elucidating their perspectives on healthcare organisation, management, and economics. ${ }^{11}$

\section{A new academic agenda}

Our suggested definition will suit the agenda of some research institutions well but may require substantial rethinking in most teaching settings. The core curriculum should be balanced and scientific and address all the core aspects of the specialty of general practice. This would result in all new general practitioners receiving relevant scientifically based learning in the disciplines of health services theory, setting of medical priorities, psychology, sociology, and ethics, as well as up to date learning in the well defined biomedical parts of their job (box).

The research agenda following from the definition demands the use of existing biomedical methods but would also require adoption of old-or even the development of new humanistic-research methods, and this must be reflected in teaching and learning research methods. All students and young doctors learn some quantitative research methods in epidemiology and statistics. In addition they must understand humanistic research methods and their outcomes, which must therefore be incorporated into undergraduate curriculums and later in specialist training for general practice. As a part of this promotion of a balanced methodological agenda, general practitioners have to find better ways of reporting their qualitative research in the general journals appearing in the recognised medical indexes, so that readers worldwide have access to valid new knowledge.

If doctors recognise and accept the suggested definition they should ideally look for ways to change their 
work pattern, to undertake this balanced, personal, and explicitly broad approach to their patients and their problems. More than other doctors, general practitioners would also see the need for evidence based training in consultation and communication skills, though such teaching and training is needed by all physicians in clinical work. ${ }^{8-10} 15-19$

It is time to embrace the new definition and to work for the goals that follow from it. The first step is to revitalise the discussion about the research agenda, the core curriculum, and the scientific contents of teaching in the general practice specialty.

We use the terms general practitioner and general practice in relation to the specialty of the "front line" doctor, though we know that some countries use the term family medicine, in part to avoid negative connotations associated with poorly trained general practitioners. We use the term specialist in general practice because it is used in many countries to assert the equality of trained general practitioners with other clinical doctors, though we know that some countries, including the United Kingdom, use the term specialist as a semantic opposite to the term generalist.

Contributors: FO fostered the idea, made the initial literature search, and drafted the manuscript. PH discussed with FO the initial idea and contributed to the literature search. All authors had intense discussions on the content of the paper and the suggested implications for research and teaching. All authors are guarantors for the content of the paper.

Funding: None.

Competing interests: None declared.

1 Donaldson MS, Yordy KD, Lohr KN, Vanselow NA, eds. Primary care America's health in a new era. Washington, DC: Institute of Medicine, 1996.
2 Lamberts H, Knottnerus JA, Hofmans SB, Klaassen A, eds. General prac tice research in Dutch academia. Amsterdam: Medical Committee, Royal Netherlands Academy of Arts and Sciences, 1994.

3 Weel C. General practice: a suitable place for clinical research. Eur J Gen Pract 1995; 1:6-7.

4 Brody H, Lansing E. The biopsychosocial model, patient-centered care, and culturally sensitive practice. J Fam Pract 1999;48:585-7.

5 Heyrman J, Spreeuwenbergh C, eds. Vocational training in general practice. Leuven: Katholieke Universiteit Leuven, 1987.

6 McWhinney IR. A textbook of family medicine. 2nd ed. New York: Oxford University Press, 1997

7 Rosser WW. Approach to diagnosis by primary care clinicians and specialists: is there a difference? J Fam Pract 1996;42:139-44.

8 Dixon DM, Sweeney KG, Pereira Gray DJ. The physician healer: ancient magic or modern science. Br J Gen Pract 1999;49:309-12.

9 McWhinney IR. William Pickles lecture 1996. The importance of being different. BrJ Gen Pract 1996;46:433-6.

10 Heath I. The mystery of general practice. London: Nuffield Provincial Hospital Trust; 1995.

11 Krasnik A. The concept of equity in health services research. Scand J Soc Med 1996;24:2-7.

12 Olesen F, Fleming D. Patient registration and controlled access to secondary care. Prerequisites for integrated care. Eur J Gen Pract 1998;4:81-3.

13 Evidence-based Medicine Working Group. Evidence-based medicine: a new approach to teaching the practice of medicine. JAMA 1992;268:2420-5

14 Malterud K. The legitimacy of clinical knowledge. Towards a medical epistemology embracing the art of medicine. Theor Med 1995;16:183-98.

15 Andersson JM. Empowering patients: issues and strategies. Soc Sci Med 1996;43:697-705.

16 Antonowsky A. Health, stress and coping. San Francisco: Jossey-Bass, 1979

17 Freeman G, Hjortdahl P. What future for continuity of care in general practice? BMJ 1997;314:1870-3

18 Tuckett D, Boulton M, Olson C, Williams A. Meeting between experts. An approach to sharing ideas in medical consultations. London: Tavistock Publications, 1985.

19 Making medical practice and education more relevant to people's needs: the con tribution of the family doctor. Geneva: World Health Organisation, 1994 (Working paper of the WHO and the World Organisation of Family Doctors.)

(Accepted 11 November 1999)

\section{When I use a word ... Modern English abusage}

When Henry Watson Fowler published his Dictionary of Modern English Usage in 1926 he could hardly have foreseen how popular it would become as a source of information about grammar, rhetoric, punctuation, spelling, and other matters related to written and spoken English. The first edition, reprinted many times, was followed by a second, edited by Ernest Gowers in 1965, and a third, edited by Robert Burchfield in 1996.

Apart from the fact that Burchfield chronicles the ways in which our use of language has changed since Fowler and Gowers, his edition differs in one major aspect-it is descriptive rather than prescriptive or proscriptive. Whereas his predecessors told us what we ought to do, Burchfield uses his large corpus of examples to tell us what we actually do. And although he often shows approval or disapproval, or states his own preferences, he generally yields to common usage, rather than to rigid rules, as the arbiter of correctness. For instance, Fowler preferred Britishism to Briticism, labelling the latter a barbarism; Burchfield simply comments that Briticism is now the more usual term in scholarly work. Of course, Fowler and Gowers are not always rigid, nor Burchfield always permissive, but the emphasis has changed.

Burchfield's text is as authoritative as Fowler's was. But his New Fowler is marred by a poor grasp of medicine and science. Take some examples. "Vaccinate," he writes, "is technically synonymous with inoculate, but in practice tends to be restricted to mean inoculate [against] smallpox." He has it the wrong way round: vaccinate technically (or at least etymologically) means to inoculate against smallpox using cowpox, but is nowadays used to mean to inoculate against any infectious disease.

Elsewhere Burchfield correctly writes that in an arithmetical progression-for example, $1,3,5,7,9$, etc-the rate of increase is much smaller than in a geometrical progression-for example, $1,2,4,8,16,32$, etc. But he then says that sometimes a geometrical progression can be used to indicate a slow rate of increase $-0.00001,0.00002,0.00004,0.00008$, etc. To be fair to
Burchfield, he has made a valiant attempt to simplify the corresponding entry by Fowler, which is hard to fathom. But he perpetuates Fowler's mistake, in failing to appreciate that these two geometrical progressions grow at exactly the same rate, presumably misled by the smallness of the absolute increments in the latter.

Burchfield's description of a calorie is oversimplified and he makes no mention of the joule. Caucasian he describes as the normal word for a white person "in American English (but rarely elsewhere)," ignoring its widespread use in the world scientific literature. He defines the centigrade scale as one in which water freezes at $32^{\circ}$ and boils at $212^{\circ}$; Celsius he defines correctly, Fahrenheit he omits (although he defines it under Celsius), and Réaumur he includes simply to note its pronunciation. And groin, he says, is "a physiological term."

But Burchfield's most curious solecism is in his explanation of the medical titles $M r$ and $D r$. "In Britain," he writes "a surgeon is normally addressed as $M r+$ surname, but in Scotland $D r$ is used for both physicians and surgeons." Having read this I thought that Burchfield must have uncritically copied Fowler and Gowers, but in fact neither of them made this assertion-it is Burchfield's alone, and I don't think that it was ever true. But perhaps he knows something about the intentions of the Scottish Assembly that the rest of us do not.

Jeff Aronson clinical pharmacologist, Oxford

We welcome articles of up to 600 words on topics such as A memorable patient, A paper that changed my practice, My most unfortunate mistake, or any other piece conveying instruction, pathos, or humour. If possible the article should be supplied on a disk. Permission is needed from the patient or a relative if an identifiable patient is referred to. We also welcome contributions for "Endpieces," consisting of quotations of up to 80 words (but most are considerably shorter) from any source, ancient or modern, which have appealed to the reader. 